\title{
The Association Between Discriminatory Experiences and Self-Reported Health Status among Asian Americans and Its Subethnic Group Variations
}

\author{
Hyunsu $\mathrm{Oh}^{1}$ (D) \\ Received: 27 April 2021 / Revised: 24 June 2021 / Accepted: 7 July 2021 / Published online: 23 July 2021 \\ (C) W. Montague Cobb-NMA Health Institute 2021
}

\begin{abstract}
Purpose Using distinct measures for racial microaggressions and discrimination, this article explored the association between discriminatory experiences and self-reported health status among Asian populations in the USA and its subethnic group variation. Methods This article investigated 4393 Asian American adults from the 2016 Post-Election National Asian American Survey (NAAS). Binary measure of self-reported health (not good/good) was accounted for. Two measures of racial microaggressions included (1) verbal microaggression and (2) behavioral microaggression. Two measures of discrimination encompassed (1) workplace discrimination and (2) institutional racism. Ethic groups were classified to (1) East Asian ( $n=1491)$, (2) Southeast Asian ( $n=1758)$, or (3) South Asian ( $n=1144)$.

Results Findings from logistic regression analyses showed that increased workplace discrimination and institutional racism yielded decreased odds of reporting good health status. The association between racial microaggressions, discrimination, and self-reported health status varied across ethnic subgroup, indicating that the verbal aggression score was more predictive for the East Asian group while institutional racism was most harmful to Southeast Asians.

Discussion Findings highlighted the racialized interpretation and its variations in self-reported health status among Asian populations. Relating to variations in experiences of racialization and attainment of socioeconomic status, disproportionate relationships of discriminatory experiences and health among Asian populations were further discussed.
\end{abstract}

Keywords Asian Americans · Self-reported health status · Racial microaggressions · Discrimination

\section{Background}

In addition to medical and pathological explanations, sociocultural factors also affect health and illness and contribute to health disparities between racial and ethnic groups. Given the persistent racial inequality in the US society, it is not surprising that health status also is racialized. Specifically, white people generally show better health outcomes than non-white populations [1-3]. Experiences of race-based and ethnicity-based

Hyunsu Oh

hoh8@ucmerced.edu

1 Department of Sociology, University of California, Merced, 5200 Lake Rd., Merced, CA 95343, USA discrimination can cause distress, anxiety, depression, and other problems that negatively affect health [4-8].

Despite a scarcity of prior research $[9,10]$, the academic discussion between discriminatory experiences and health conditions is also applicable to various Asian populations. Asian identity in America has been racialized throughout its sociocultural and political history [11-13]. Asian populations often experience racism ranging from more subtle forms of microaggression to more overt types of discrimination [11, 14-17]. These experiences can have significant negative effects on physical and psychological wellbeing [9, 10, 18-21]. In particular, using cross-sectional social survey data with Asian Americans, prior research showed that the more experiences of discrimination [10] and racial microaggressions [9] are linked to the worse selfreported health status for Asian populations. 
Building based on the literature $[9,10]$, this research explored the association between discriminatory experiences and self-reported health status among Asian populations in the USA using data from a nationally representative social survey, the 2016 Post-Election National Asian American Survey (NAAS). In order to capture race-based discriminatory experiences, based on the NAAS survey questions, two measures of racial microaggressions and two measures of discrimination were considered. For racial microaggressions, behavioral microaggressions are subtle but racially biased and hostile actions toward racial minorities that signal exclusion and scorn [16, 22, 23]; verbal microaggressions are "derogatory racial slights and insults" [23 , p. 273]. These actions are directed toward a minority population to convey otherness and judgement [24]. For discrimination, workplace discrimination signifies discriminatory practices and prejudices at workplaces toward people of color, and institutional racism refers to "racially discriminatory policies or practices ingrained in institutional mechanisms and processes" $[10$, p. 6]. Institutional discrimination is connected to systemic inequalities in social and political infrastructures (e.g., racism in the housing market and criminal justice system), and it has important negative effects on public health $[10,18,25]$.

In addition, to ascertain the association between discriminatory experiences and self-reported health status among Asian populations, this research also explored its subethnic group variations. The Asian racial category includes more than 20 subethnic groups, each of which has distinct sociocultural characteristics and immigration histories. Such differences have led to variations in experiences of racialization and attainment of socioeconomic status that would shape health outcomes. For instance, during the last decades, East Asian populations have achieved near socioeconomic parity with Whites due to high levels of educational and occupational achievements [13, 26, 27]. And yet, although it has been argued that overt systemic racism has been eradicated in today's colorblind America [26], East Asian Americans still face everyday discrimination that compromises their health, despite their socioeconomic successes $[14,20,28]$. Whereas studies indicate that contrary to East Asian Americans, Southeast Asian Americans have maintained the minority status $[13,26,29]$ that are more comparable to those of other racial minorities, such as Latinx and Black populations, by being systemically penalized in societal institutions, including education [30, $31]$, housing markets $[32,33]$, workplaces, and labor markets [17, 34]. Those variations in experiences of racialization and attainment of socioeconomic status would lead to varying relationships between discriminatory experiences and self-reported health status between Asian subethnic groups.

\section{Methods}

\section{Data and Variables}

The 2016 NAAS comprised 4393 telephone interviews with Asian populations to solicit their demographic information, immigration status, political affiliations, attitudes toward public policies and other racial groups, experiences of racism, self-reported health status, and other information. Interviews were carried out between November 2016 and March 2017 using either English or other "native languages" each respondent wanted. Using registered voter and commercial vendor samples and classified for ethnic and national origin, it provided nationally representative dataset for Asian American adults, weighted by ethnicity, age, gender, region of stay, and so on. ${ }^{1}$ As a unique and comprehensive social survey of Asian populations in the USA, it is broadly applied in social science research to ascertain the identities, experiences, and attitudes of these populations $[9$, 17, 35-37].

To measure self-reported health status, I used the answers to the NAAS question, "How would you rate your overall health in the past year?" Responses ranged from 1 (excellent) to 5 (poor). Using this, I constructed the variable self-reported health status as a binary measure of self-rated health $(0=$ not good and $1=$ good $)$. Self-reported NAAS responses of "Excellent," "Very Good," and "Good" were coded as 1, whereas responses of "Fair" and "Poor" were coded as 0. Excluding non-codable and missing responses, $75.8 \%$ of respondents reported good overall health status ( $n=3244)$, compared to $24.2 \%$ who rated their health as not $\operatorname{good}(n=1036)$.

The 2016 NAAS also asked about respondents' experiences with racial microaggression and discrimination. For example, respondents were asked to describe how they have been treated in everyday encounters with strangers. To construct an index of behavioral microaggression, I focused on answers to four yes/no statements from the NAAS asking about experiences of indignity caused by others' behaviors: (1) "You received poorer service than other people at restaurants or stores," (2) "People act as if you don't speak English," (3) "People act as if they are afraid of you," and (4) "People act as if they think you are dishonest." I coded "no" responses as 0 and "yes" responses as 1 and then added them without weighting. The behavioral

\footnotetext{
${ }^{1}$ Source: Ramakrishnan et al. Asian American Voices: Results from the 2016 Post-Election National Asian American Survey (http://naasurvey.com/wpcontent/uploads/2017/05/NAAS16-post-election-report.pdf)
} 
microaggression score ranged from 0 to 4 , with higher scores indicating more experiences of these microaggressions $(M=.595$, S.E. $=.962)$. As a single scale, the score was internally consistent as Cronbach's alpha being equal to .667 . To construct an index of verbal microaggression, I used responses to three yes/ no questions: (1) "You are called names or insulted," (2) "You are threatened or harassed," and (3) "People mispronounce your name." Adding those three responses (Cronbach's $\alpha=.483$ ), scores ranged from 0 to 3 , with higher numbers presenting more experiences of verbal microaggression $(M=.841$, S.E. $=.818)$.

To account for Asian Americans' experiences of discrimination, I used two measures, workplace discrimination and institutional racism. The first measure was based on answers to three NAAS questions: (1) "Have you ever been unfairly denied a promotion?" (2) "Have you ever been unfairly fired from a job?" and (3) "For unfair reasons, do you think you have ever not been hired for a job?" As a non-weighted additive index using those three discrimination experiences (Cronbach's $\alpha=.668$ ), the variable for workplace discrimination ranged from 0 to 3 , with higher values representing more such discrimination in daily life $(M=.359$, S.E. $=.739)$. To ascertain experiences of institutional racism, responses to the following three NAAS questions were used: (1) "Have you ever been unfairly stopped, searched, questioned, physically threatened, or abused by the police?" (2) "Do think you have ever been unfairly prevented from moving into a neighborhood because the landlord or a realtor refused to sell or rent you a house or apartment?" and (3) "Have you ever moved into a neighborhood where neighbors made life difficult for you or your family?" Adding those items (Cronbach's $\alpha=$ .487), the index of institutional racism varied from 0 to 3, with a mean of .263 and standard deviation of .583.

Subethnic group variations were assessed using three ethnic origin group labels: East Asia (33.9\%), Southeast Asia (40.0\%), and South Asia (26.0\%). Among the 10 ethnic groups surveyed by the NAAS, I assigned Chinese American $(n=475)$, Japanese American $(n=517)$, and Korean American $(n=499)$ respondents to the East Asia group; Cambodian American $(n=401)$, Filipino American $(n=505)$, Hmong American $(n=351)$, and Vietnamese American $(n=501)$ respondents to the Southeast Asia group; and Bangladeshi American $(n=320)$, Indian American $(n=$ 504), and Pakistani American $(n=320)$ respondents to the South Asia group.

I also controlled for other sociodemographic characteristics. For example, age in years was included. I used a dummy variable for female as a reference category of gender. Having a college degree was included to control for educational attainment of respondents. A variable for US born, as compared to foreign born, was added to account for place of birth. Marital status was classified as never married, married, or separated, divorced, or widowed. The natural $\log$ of family income also was added. Finally, the region of US residence (Northwest, Midwest, South, or West) was included. Some variables have missing values. And yet, the missing-data mechanism for this dataset is viewed as missing at random and only depends on the fully observed covariates. ${ }^{2}$ Such missingness was dealt with listwise deletion in multivariate analyses.

\section{Analytic plan}

To examine the association between discriminatory experiences and self-reported health status and its subethnic group variations, I first ran a series of analysis of variance (ANOVA) by comparing the subethnic group means of variables for discriminatory experiences and self-reported health status.

Then, I conducted a binary logistic regression analysis using self-reported health status as the dependent variable. Using a binary dependent variable enabled identification of direct and/or indirect relationships between the explanatory variables and the outcome variable. Adding indicators for both types of discriminatory experiences (microaggressions and discrimination), model 1 ascertained how different levels of those experiences yield differences in odds of reporting good health status. By including variables for ethnic origin, model 3 accounted for ethnic variation in self-reported health status. Finally, using two-way interaction terms of ethnic origin and microaggressions with ethnic origin discrimination, model 4 conceptualized how ethnic origin mediates the association of discriminatory experiences and self-reported health status. Figure 1 further visualized the interaction effect by estimating differences in odds of reporting good health in accordance with predicted variations in levels of discriminatory experiences. For the data analysis, Stata (version 13) was used.

\section{Results}

Table 1 reports descriptive statistics related to the selfreported health status, microaggression, and

\footnotetext{
${ }^{2}$ More specifically, variables for gender, ethnic origin, having a college degree, place of birth, and region of residency were fully observed while variables for self-reported health, verbal and behavioral microaggressions, workplace discrimination, institutional racism, age, marital status, and family income had missing components. Little's covariate-dependent missingness (CDM) test gave a $\chi^{2}$ distance of 1969.74 with degrees of freedom 3321 and $p$ value 1.00. See [38] for details on Little's CDM test.
} 
Table 1 Ethnic variations in health status, microaggression, and discrimination, by ethnic origin

\begin{tabular}{|c|c|c|c|c|c|}
\hline & \multirow[t]{2}{*}{ Total } & \multicolumn{3}{|l|}{ Ethnic origin } & \multirow[t]{2}{*}{$F$ ratio } \\
\hline & & East & Southeast & South & \\
\hline Self-reported health status $(1=$ good $)$ & $.758(.428)$ & $.747(.435)$ & $.702(.458)$ & $.862(.345)$ & $48.74 * * *$ \\
\hline \multicolumn{6}{|l|}{ Microaggression } \\
\hline Behavioral microaggression & $.595(.962)$ & $.529(.874)$ & $.640(1.011)$ & $.619(.993)$ & $5.53 * *$ \\
\hline Verbal microaggression & $.841(.818)$ & $.771(.773)$ & $.810(.836)$ & $.979(.833)$ & $22.87 * * *$ \\
\hline \multicolumn{6}{|l|}{ Discrimination } \\
\hline Workplace discrimination & $.359(.739)$ & $.325(.704)$ & $.321(.709)$ & $.463(.816)$ & $14.43 * * *$ \\
\hline Institutional racism & $.263(.583)$ & $.220(.528)$ & $.255(.575)$ & $.330(.653)$ & $11.77 * * *$ \\
\hline$N$ & 4393 & 1491 & 1758 & 1144 & \\
\hline
\end{tabular}

Note: $* * p<.01 ; * * * p<.001$

Standard error in parentheses

discrimination variables among the different Asian subethnic groups. For self-reported health status, although the odds of reporting good health were quite high for all respondents $(75.8 \%)$, the South Asia $(86.2 \%)$ group was more likely than the other two groups to rate their health as good, followed by the East $(74.7 \%)$ and Southeast Asia (70.2\%) groups.

I found subethnic group variations in discriminatory experiences among Asian Americans. In general, the East Asia group (China, Korea, and Japan) experienced lower rates of microaggression than the Southeast and South Asia groups. For instance, the East Asia group (.529) reported the lowest level of racially hostile behaviors toward them, compared to the South Asia (.619) and Southeast Asia (.640) groups. Further, the East Asia group (.771) reported substantially lower rates of verbally abusive aggressions than did the Southeast Asia (.810) and South Asia (.979) groups. Results from analysis of variance (ANOVA) showed that these ethnic group variations are statistically significant (for behavioral aggression, $F=5.53, p<.01$; for verbal aggression, $F=22.87, p<$ $.001)$.

In terms of experiences of discrimination, the Southeast Asia group (Cambodian-, Filipino-, Hmong-, and Vietnamese-American respondents), reported a similar level of workplace discrimination as the East Asia group (.321 versus .325). The South Asia group (.463) reported significantly higher levels of workplace discrimination than the other two ethnic groups $(F=$ $14.43, p<.001$ ), and they experienced the highest overall level of institutionalized racism (.330), followed by the Southeast Asia (.255) and East Asia (.220) groups $(F=11.77, p<.001)$.
In addition to the univariate findings, Table 2 presents the multivariate results from the logistic regression models predicting self-reported health status among Asian Americans. Across all models, variables for age, gender, education, place of birth, marital status, family income (logged), and region of stay were controlled but omitted in Table 2 for brevity.

In detail, adding the two variables each for microaggression (behavioral and verbal) and discrimination (workplace and institutional), as well as control variables, model 1 describes how racially discriminatory experiences affect Asian Americans' self-reported health status. All else equal, institutional racism was negatively associated with good health status $(b=-.219, p<.01)$. More specifically, a 1 -unit increase in the index of institutional racism was associated with about a $20 \%$ decrease $\left(\exp ^{-.219}=.803\right)$ in the odds of reporting good health. Although other indicators for behavioral $(b=-.004)$ or verbal $(b=-.042)$ microaggressions and workplace discrimination $(b=-.114)$ also were negatively associated with reporting good health status, these were statistically not significant.

To assess ethnic variation in these responses, model 2 included dummy variables for Southeast Asian or South Asian ethnicity (the omitted reference category was East Asian). In this model, I found a disparity among Asian Americans in accordance with ethnic group identity. That is, accounting for other sociodemographic variables, both the Southeast Asia $(b$ $=.205, p<.05)$ and South Asia $(b=.470, p<.001)$ groups were more likely than the East Asia group to report good health status. For discrimination, increased experiences of institutional racism were connected to 
Table 2 Results from logistic regression models predicting heath status among Asian Americans

\begin{tabular}{llll}
\hline & Model 1 & Model 2 & Model 3 \\
\hline Behavioral microaggression & $-.004(.056)$ & $.003(.056)$ & $.026(.096)$ \\
Verbal microaggression & $-.042(.066)$ & $-.049(.067)$ & $-.196 *(.110)$ \\
Workplace discrimination & $-.114(.070)$ & $-.121^{*}(.070)$ & $-.094(.121)$ \\
Institutional racism & $-.219 * *(.090)$ & $-.232^{* *(.091)}$ & $.018(.165)$ \\
Southeast Asian & & $.205^{*}(.111)$ & $.136(.151)$ \\
South Asian & & $.470^{* * *(.153)}$ & $.429 *(.225)$ \\
Southeast Asian $\times$ Behavioral & & & $.001(.127)$ \\
South Asian $\times$ Behavioral & & & $-.127(.164)$ \\
Southeast Asian $\times$ Verbal & & & $.206(.146)$ \\
South Asian $\times$ Verbal & & & $.286(.195)$ \\
Southeast Asian $\times$ Workplace & & & $.030(.160)$ \\
South Asian $\times$ Workplace & & & $-.169(.194)$ \\
Southeast Asian $\times$ Institutional & & & $-.445^{* *}(.211)$ \\
South Asian $\times$ Institutional & $-3.533^{* * *}(.593)$ & $-.213(.253)$ \\
Constant & -1461.968 & -1456.911 & $-3.826^{* * *}(.632)$ \\
Log likelihood & 3026 & 3026 & -1452.820 \\
$N$ & & 3026 \\
\hline
\end{tabular}

Note: For all models, covariates for age, gender, education (college graduated or not), place of birth (US born or not), marital status (never married, married, separated, divorced, or widowed), logged family income, and region of residence (Northeast, Midwest, South, or West) were included but are not presented in this table

${ }^{\mathrm{a}}$ East Asian omitted as a reference category

$* p<.05, * * p<.01, * * * p<.001$

Standard error in parentheses

worse self-reported health $(b=-232, p<.01)$. In addition to institutional racism, ethnic origin was significantly related to differences in levels of workplace discrimination. An increase in workplace discrimination yielded a decrease in selfreported health $(b=-.121, p<.05)$.

Model 3 added two-way interaction terms between subethnic group and both microaggression types and between subethnic group and both discrimination types. This modelling strategy showed that ethnic group membership moderated the relationships of racial microaggression and discrimination on health status. Figure 1 illustrates the interaction effects.

Panel a of Fig. 1 depicts the estimates of good health status, by levels of verbal microaggression, across the three Asian American ethnic groups. All else equal, it predicts differences in odds of reporting good health status along with corresponding variations in the level of verbal microaggression. It indicates that the verbal aggression score was more predictive for the East Asian group than for Southeast Asia and South Asia groups and that the lowest probability of reporting good health was associated with the highest level of verbal aggression. That is, with all else equal, experiences of verbal microaggression were most strongly associated with worse health status among East Asian American respondents. More specifically, a 1-unit increase in the verbal aggression index yielded an $18 \%$ decrease in reporting good health status in the East Asia group (in model 3 of Table 2, $b=-.196 . p<.05$, $\exp ^{-.196}=.822$ ). In the Southeast Asia and South Asia groups, verbal aggression did not substantially shape self-reported health status.

The findings provide evidence supporting subethnic group differences in exposure to different levels of institutional racism and explaining how that exposure affects the probability of reporting good health. Similarly, panel b of Fig. 1 further estimates the relationship between the institutional racism score and self-reported health status across the three Asian American ethnic groups. All three ethnic groups start at roughly the same point. At subsequent levels of institutional racism, however, Southeast and South Asian Americans reported worse health, whereas the institutional racism score was not predictive for East Asian Americans' self-reported health. Importantly, the Southeast Asia group experienced more institutional racism, and these respondents were predicted to report the lowest level of health (model 3 of Table $2, b=-.445 . p<.01$ ). Other than verbal 
Fig. 1 Predicted probabilities of reporting good health, by ethnic origin. a By levels of verbal aggression. b By levels of institutional racism (a) By levels of verbal aggression

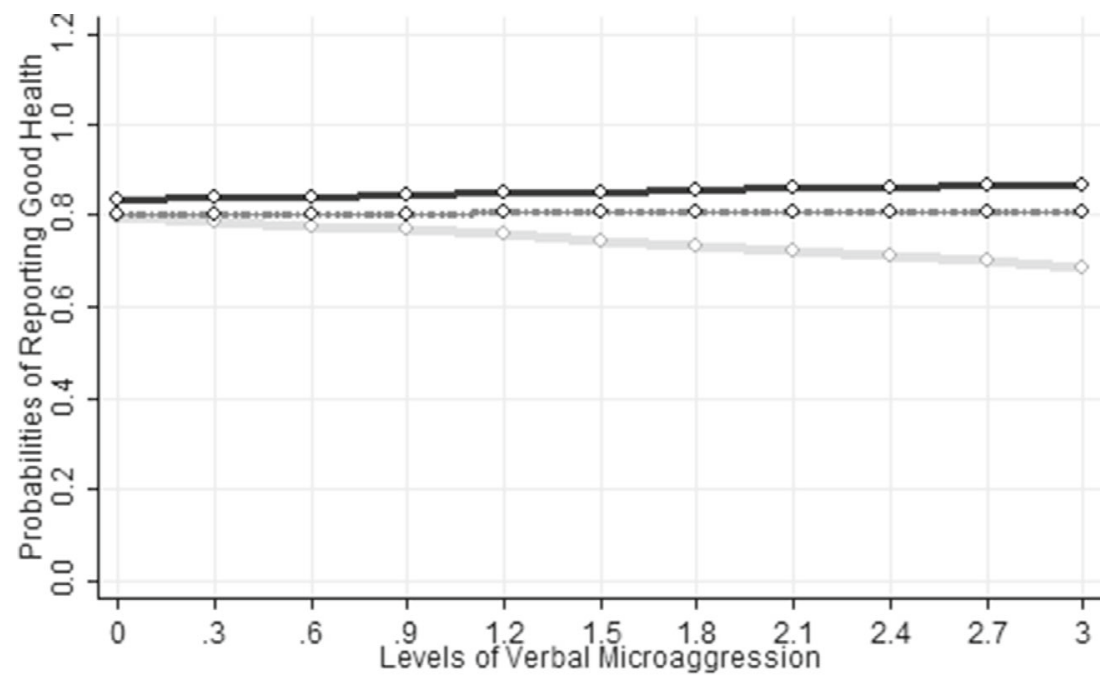

East Asian

South Asian

\section{(b) By levels of institutional racism}

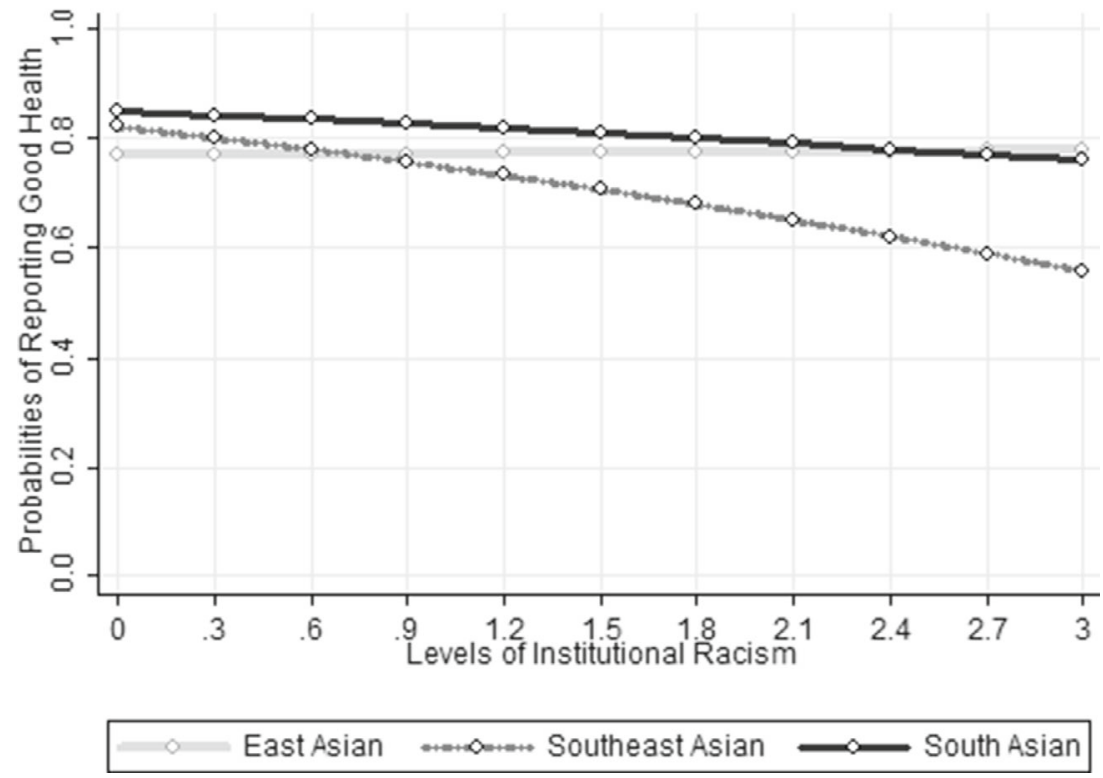

aggression and institutional racism, there was no statistically significant interaction between ethnic origin, behavioral microaggression, and workplace discrimination.

\section{Discussion}

Investigating data from the 2016 NAAS, I found differences among various Asian American populations in their selfreported health status and experiences of racism. Among population subgroups, those in the South Asia group (i.e., Bangladeshi-, Indian-, and Pakistani-American) reported the highest levels of self-reported health status, followed by the East Asia (i.e., Korean-, Chinese-, and Japanese-American) and Southeast Asia (i.e., Cambodian-, Filipino-, Hmong-, and Vietnamese-American) groups. Further, using two separate typologies for racial microaggression (behavioral aggression and verbal aggression) and discrimination (workplace discrimination and institutional racism), I found that South Asian Americans experienced the most racial discrimination 
(e.g., verbal aggression, workplace discrimination, and institutional racism) across three Asian American ethnic groups, though the Southeast Asia group experienced the most behavioral aggression.

The multivariate findings support prior studies $[9,10$, 18-21] showing that increased racial discrimination was associated with worse health status among Asian populations in America. For NAAS respondents, increased workplace discrimination and institutional racism yielded decreased odds of reporting good health status. More importantly, I found that the ethnic subgroup mediated the association between racial microaggressions, discrimination, and self-reported health status. All else equal, the verbal aggression score was more predictive for the East Asian group, indicating that verbal aggression was most harmful to them. However, East Asians were not sensitive to institutional racism, which was more predictive for the South and Southeast Asian group, with the most detrimental effect on Southeast Asians.

Given the diversity and variability of those with Asian heritage in America, scholars suggest unpacking the panethnic label of "Asian" in health research [9, 10, 39]. Along with variations in experiences of racialization and attainment of socioeconomic status, findings affirmed that among Asian American populations, for the subgroups who have severely discriminated by institutional penalties, those practices of institutional racism are more influential for predicting poor health status. Otherwise, even if they have achieved socioeconomic successes, racially hostile aggressions are still connected to worse health for a high-achieving Asian subgroup. Thus, to account for variations in the determinants and results of health disparities among Asian populations in America, their diversity must be acknowledged and considered.

I acknowledge several limitations of this study. Primary variables of interest-microaggressions, discrimination, and self-reported health status-were self-rated and subjective. Relatedly, although constructing scales for microaggressions and discrimination were internally reliable, it is unsure that those indices are further valid beyond this dataset. In addition, although prior studies indicate intersectional effects between race/ethnicity, gender, and social class on health outcomes of minority populations [5, 6], I found no direct or indirect association between gender, social class, and self-reported health status. More importantly, although the South Asian subgroup reported the highest levels of racial microaggression and discrimination, they also reported the best health status, collectively. My models did not provide enough detail to explain why discriminatory experiences among South Asian populations were not linked to their health status.

Nevertheless, by showing a racialized interpretation of variations in health status among Asian populations, this study contributes to the literature on race and health among Asian Americans. Future studies may benefit from using other quantitative datasets and techniques to further assess the associations between discriminatory experiences and various health outcomes, such as anxiety, depression, and substance use. Qualitative methods, such as in-depth interviews and participatory observations, may be useful to discuss the mechanisms and determinants of variations in subethnic groups, such as the South Asian peculiarity observed in this study.

In recent days, the COVID-19 pandemic may threaten the status quo of Asian populations in the USA. Asians and Asian Americans, regardless of their connection to China, have been blamed for the pandemic [21, 40, 41]. As a mechanism of aggression, discrimination, and even hate crimes, this racialized condemnation may have far-reaching effects on Asian populations [40], including worsening health conditions [21, 41]. This study may also provide implications to assess the impacts of the COVID-19 pandemic on wellness of Asian American populations.

Author Contribution Not applicable

Funding The author received no financial support for the research and/or authorship of this article.

Data Availability The data used in this article (2016 NAAS) is publicly available on the National Asian American Survey website (http:// naasurvey.com/data/).

Code Availability Stata codes for statistical analyses are available upon request.

\section{Declarations}

Conflict of Interest The author declares no competing interest.

\section{References}

1. Vega WA, Rumbaut RG. Ethnic minorities and mental health. Annu Rev Sociol. 1991;17(1):351-83. https://doi.org/10.1146/ annurev.so.17.080191.002031.

2. Williams DR, Collins C. US socioeconomic and racial differences in health: patterns and explanations. Annu Rev Sociol. 1995;21(1): 349-86. https://doi.org/10.1146/annurev.so.21.080195.002025.

3. Williams DR, Mohammed SA. Racism and health: pathways and scientific evidence. Am Behav Sci. 2013;57(8):1152-73. https:// doi.org/10.1177/0002764213487340.

4. Espinosa A. Discrimination, self-esteem, and mental health across ethnic groups of second-generation immigrant adolescents. J Racial Ethn Health Disparities. 2020:1-12. https://doi.org/10.1007/ s40615-020-00917-1.

5. Grollman EA. Multiple forms of perceived discrimination and health among adolescents and young adults. J Health Soc Behav. 2012;53(2):199-214. https://doi.org/10.1177/0022146512444289.

6. Seng JS, Lopez WD, Sperlich M, Hamama L, Meldrum CDR. Marginalized identities, discrimination burden, and mental health: empirical exploration of an interpersonal-level approach to modeling intersectionality. Soc Sci Med. 2012;75(12):2437-45. https:// doi.org/10.1016/j.socscimed.2012.09.023.

7. Stone AL, Carlisle SE. Examining race/ethnicity differences in the association between the experience of workplace racial 
discrimination and depression or negative emotions. J Racial Ethn Health Disparities. 2019;6(5):874-82. https://doi.org/10.1007/ s40615-018-0524-8.

8. Woo B. Racial discrimination and mental health in the USA: testing the reverse racism hypothesis. J Racial Ethn Health Disparities. 2018;5(4):766-73. https://doi.org/10.1007/s40615-017-0421-6.

9. Nicholson HL Jr, Mei D. Racial microaggressions and self-rated health among Asians and Asian Americans. Race Soc Probl. 2020;12:209-18. https://doi.org/10.1007/s12552-020-09293-1.

10. $\mathrm{Oh} \mathrm{H}$. The impact of racial discrimination on health disparities among Asian Americans. In: Kronenfeld JJ, editor. Race, ethnicity, gender and other social characteristics as factors in health and health care disparities (Vol 38 of Research in the Sociology of Health Care, pp 3-14): Emerald Publishing Limited; 2020. https://doi.org/ 10.1108/S0275-495920200000038005.

11. Hsu MY. The good immigrants: how the yellow peril became the model minority: Princeton University Press; 2017.

12. Kim CJ. The racial triangulation of Asian Americans. Polit Soc. 1999;27(1):105-38. https://doi.org/10.1177/ 0032329299027001005 .

13. Sakamoto A, Goyette KA, Kim C. Socioeconomic attainments of Asian Americans. Annu Rev Sociol. 2009;35:255-76. https://doi. org/10.1146/annurev-soc-070308-115958.

14. Chou RS, Feagin JR. Myth of the model minority: Asian Americans facing racism: Routledge; 2015.

15. Lee JC, Kye S. Racialized assimilation of Asian Americans. Annu Rev Sociol. 2016;42:253-73. https://doi.org/10.1146/annurev-soc081715-074310.

16. Sue DW, Bucceri J, Lin AI, Nadal KL, Torino GC. Racial microaggressions and the Asian American experience. Cult Divers Ethn Minor Psychol. 2007;13(1):72-81. https://doi.org/10. 1037/1099-9809.13.1.72.

17. $\mathrm{Yu} \mathrm{HH}$. Revisiting the bamboo ceiling: perceptions from Asian Americans on experiencing workplace discrimination. Asian Am J Psychol. 2020;11(3):158-67. https://doi.org/10.1037/ aap0000193.

18. Gee GC. A multilevel analysis of the relationship between institutional and individual racial discrimination and health status. Am J Public Health. 2008;98(Supplement_1):S48-56. https://doi.org/10. 2105/AJPH.98.Supplement_1.S48.

19. Gee GC, Ro A, Shariff-Marco S, Chae D. Racial discrimination and health among Asian Americans: evidence, assessment, and directions for future research. Epidemiol Rev. 2009;31(1):130-51. https://doi.org/10.1093/epirev/mxp009.

20. Jang Y, Chiriboga DA, Kim G, Rhew S. Perceived discrimination, sense of control, and depressive symptoms among Korean American older adults. Asian Am J Psychol. 2010;1(2):129-35. https://doi.org/10.1037/a0019967.

21. Zhang M, Gurung A, Anglewicz P, Baniya K, Yun K. Discrimination and stress among Asian refugee populations during the COVID-19 pandemic: evidence from Bhutanese and Burmese refugees in the USA. J Racial Ethn Health Disparities. 2021:1-9. https://doi.org/10.1007/s40615-021-00992-y.

22. Miles ML, Brockman AJ, Naphan-Kingery DE. Invalidated identities: the disconfirming effects of racial microaggressions on Black doctoral students in STEM. J Res Sci Teach. 2020;57(10):1608-31. https://doi.org/10.1002/tea.21646.

23. Sue DW, Capodilupo CM, Torino GC, Bucceri JM, Holder A, Nadal KL, et al. Racial microaggressions in everyday life: implications for clinical practice. Am Psychol. 2007;62(4):271-86. https:// doi.org/10.1037/0003-066X.62.4.271.

24. Perez Gomez J. Verbal microaggressions as hyper-implicatures. J Polit Philos. 2020:1-29. https://doi.org/10.1111/jopp.12243.
25. Saleem FT, Lambert SF. Differential effects of racial socialization messages for African American adolescents: personal versus institutional racial discrimination. J Child Fam Stud. 2016;25(5):138596. https://doi.org/10.1007/s10826-015-0326-0.

26. Bonilla-Silva E. Racism without racists: color-blind racism and the persistence of racial inequality in America. 4th ed: Rowman \& Littlefield; 2014.

27. Sakamoto A, Woo H. The socioeconomic attainments of secondgeneration Cambodian, Hmong, Laotian, and Vietnamese Americans. Sociol Inq. 2007;77(1):44-75. https://doi.org/10.1111/ j.1475-682X.2007.00177.x.

28. Benner AD, Kim SY. Intergenerational experiences of discrimination in Chinese American families: influences of socialization and stress. J Marriage Fam. 2009;71(4):862-77. https://doi.org/10. 1037/a0016119.

29. Teranishi RT. Yellow and Brown: emerging Asian American immigrant populations and residential segregation. Equity Excell Educ. 2004;37(3):255-63. https://doi.org/10.1080/ 10665680490491551

30. Ngo B. Learning from the margins: the education of Southeast and South Asian Americans in context. Race Ethn Educ. 2006;9(1):5165. https://doi.org/10.1080/13613320500490721.

31. Ngo B, Lee SJ. Complicating the image of model minority success: a review of Southeast Asian American education. Rev Educ Res. 2007;77(4):415-53. https://doi.org/10.3102/0034654307309918.

32. Turner MA, Ross SL, Galster GC, Yinger J. Discrimination in metropolitan housing markets: national results from Phase I HDS 2000. Washington, DC: The Urban Institute; 2002.

33. Turner, M. A. \& Ross, S. L. (2003) Discrimination in metropolitan housing markets phase II: Asians and Pacific Islanders. Economics Working Paper, 200318.

34. De Castro AB, Gee GC, Takeuchi DT. Workplace discrimination and health among Filipinos in the United States. Am J Public Health. 2008;98(3):520-6. https://doi.org/10.2105/AJPH.2007. 110163.

35. Ju DH. Factors shaping Asian Americans' attitudes toward homosexuality. Ethn Racial Stud. 2021:1-24. https://doi.org/10.1080/ 01419870.2021 .1884732

36. Lu F. The dual identity of Asian Americans. Soc Sci Q. 2020;101(5):1869-84. https://doi.org/10.1111/ssqu.12831.

37. Xiao H, Bass LE. Who votes among Asian American ethnic subgroups? Socius. 2021;7:1-13. https://doi.org/10.1177/ 2378023121996852.

38. Li C. Little's test of missing completely at random. Stata J. $2013 ; 13$ (4):795-809. https://doi.org/10.1177/ $1536867 X 1301300407$.

39. Lo CC, Yang PQ, Cheng TC, Ash-Houchen W. Explaining health outcomes of Asian immigrants: does ethnicity matter? J Racial Ethn Health Disparities. 2020;7(3):446-57. https://doi.org/10.1007/ s40615-019-00673-x.

40. Li, Yao, and Harvey L. Nicholson Jr. "When "model minorities" become "yellow peril" - othering and the racialization of Asian Americans in the COVID-19 pandemic." Sociology Compass 15, no. 2 (2021): e12849. https://doi.org/10.1111/soc4.12849

41. Tessler H, Choi M, Kao G. The anxiety of being Asian American: hate crimes and negative biases during the COVID-19 pandemic. Am J Crim Justice. 2020;45(4):636-46. https://doi.org/10.1007/ s12103-020-09541-5.

Publisher's Note Springer Nature remains neutral with regard to jurisdictional claims in published maps and institutional affiliations. 